\title{
DYRK1A suppression attenuates HIF-1 $\alpha$ accumulation and enhances the anti-liver cancer effects of regorafenib and sorafenib under hypoxic conditions
}

\author{
CHONG ZHANG ${ }^{1}$, LIN-WEN WU ${ }^{1}$, ZHI-DI LI ${ }^{1}$, MAN-MAN ZHANG ${ }^{1}$, \\ $\mathrm{JIE} \mathrm{WU}^{3}$, FEI-HUA DU ${ }^{1}$, LING-HUI ZENG ${ }^{1}$ and YANG-LING $\mathrm{LI}^{2}$ \\ ${ }^{1}$ Department of Pharmacology, School of Medicine, Zhejiang University City College, Hangzhou, Zhejiang 310015; \\ ${ }^{2}$ Department of Clinical Pharmacology, Key Laboratory of Clinical Cancer Pharmacology and \\ Toxicology Research of Zhejiang, Affiliated Hangzhou First People's Hospital, Zhejiang University School of Medicine, \\ Hangzhou, Zhejiang 310006; ${ }^{3}$ School of Pharmaceutical and Materials Engineering and Institute for Advanced Studies, \\ Taizhou University, Taizhou, Jiangsu 318000, P.R. China
}

Received November 1, 2021; Accepted January 27, 2022

DOI: $10.3892 /$ ijo.2022.5335

\begin{abstract}
Hypoxia promotes drug resistance and induces the expression of hypoxia inducible factor (HIF)-1 $\alpha$ in liver cancer cells. However, to date, no selective HIF-1 $\alpha$ inhibitor has been clinically approved. The aim of this study is to investigate a drug-targetable molecule that can regulate HIF-1 $\alpha$ under hypoxia. The present study demonstrated that hyperactivation of dual-specificity tyrosine-phosphorylation-regulated kinase $1 \mathrm{~A}$ (DYRK1A)/HIF-1 $\alpha$ signaling was associated with an increased risk of liver cancer. In addition, DYRK1A knockdown using small interfering RNA transfection or treatment with harmine, a natural alkaloid, significantly reduced the protein expression levels of HIF-1 $\alpha$ in liver cancer cells under hypoxic conditions in vitro. Conversely, DYRK1A overexpression-vector transfection in liver cancer cell lines notably induced HIF-1 $\alpha$ expression under the same conditions. Furthermore, DYRK1A was shown to interact and activate STAT3 under hypoxia to
\end{abstract}

Correspondence to: Dr Ling-Hui Zeng, Department of Pharmacology, School of Medicine, Zhejiang University City College, 51 Huzhou Street, Hangzhou, Zhejiang 310015, P.R. China E-mail: zenglh@zucc.edu.cn

Dr Yang-Ling Li, Department of Clinical Pharmacology, Key Laboratory of Clinical Cancer Pharmacology and Toxicology Research of Zhejiang, Affiliated Hangzhou First People's Hospital, Zhejiang University School of Medicine, 261 Huansha Road, Hangzhou, Zhejiang 310006, P.R. China

E-mail: liyangling1215@163.com

Abbreviations: CHX, cycloheximide; DYRK1A, dual-specificity tyrosine-phosphorylation-regulated kinase 1A; HIF-1 $\alpha$, hypoxia inducible factor-1 $\alpha$; IP, immunoprecipitation; Mcl-1, myeloid cell leukemia-1; PARP, poly(ADP-ribose) polymerase; SRB, sulforhodamine B; TBST, TBS-Tween

Key words: DYRK1A, HIF-1 $\alpha$, liver cancer, hypoxia, regorafenib regulate HIF-1 $\alpha$ expression. These findings indicated that DYRK1A may be a potential upstream activator of HIF-1 $\alpha$ and positively regulate HIF-1 $\alpha$ via the STAT3 signaling pathway in liver cancer cells. Additionally, treatment with harmine attenuated the proliferative ability of liver cancer cells under hypoxic conditions using sulforhodamine B and colony formation assay. Furthermore, DYRK1A knockdown could significantly enhance the anti-liver cancer effects of regorafenib and sorafenib under hypoxia. Co-treatment with harmine and either regorafenib or sorafenib also promoted cell death via the STAT3/HIF-1 $\alpha /$ AKT signaling pathway under hypoxia using PI staining and western blotting. Overall, the results from the present study suggested that DYRK1A/HIF-1 $\alpha$ signaling may be considered a novel pathway involved in chemoresistance, thus providing a potentially effective therapeutic regimen for treating liver cancer.

\section{Introduction}

Liver cancer is the sixth most commonly diagnosed cancer; it can be resistant to the majority of anticancer therapies and is the third leading cause of cancer-related death worldwide (1). Liver cancer is one of the most hypoxic tumors, with a median oxygen level of $0.8 \%$. Therefore, the hypoxic microenvironment is a typical characteristic of liver cancer (2). It has been reported that hypoxia induces hypoxia inducible factor (HIF-1 $\alpha$ ) upregulation, promotes drug resistance and metastasis, and enhances the aggressiveness of liver cancer cells (3). Therefore, targeting tumor hypoxia/HIF-1 $\alpha$ could be considered as an attractive strategy for developing novel anti-liver cancer drugs and enhancing the chemosensitivity of liver cancer cells $(4,5)$. Although numerous HIF-1 $\alpha$ inhibitors have been identified, no selective HIF-1 $\alpha$ inhibitor has been clinically approved. However, several clinically approved drugs, such as vorinostat and digitoxin, have been shown to directly or indirectly inhibit HIF-1 $\alpha$ expression (6). Therefore, alternative strategies for implementing HIF-1 $\alpha$ suppression are urgently needed. 
Dual-specificity tyrosine-phosphorylation-regulated kinase 1A (DYRK1A) is a serine/threonine kinase located on human chromosome 21. Previous studies have suggested that DYRK1A overexpression is involved in the development of neurodegenerative diseases, including Down's syndrome, Alzheimer's, Parkinson's and Huntington's disease $(7,8)$. In addition to its role in brain development, DYRK1A contributes to the progression and development of a number of malignancies, such as glioblastoma multiform and pancreatic ductal adenocarcinoma $(9,10)$. Recent studies have shown that DYRK1A could serve a significant role in drug resistance, since DYRK1A silencing could enhance the anticancer effects of AZD9291 or Bcl-2 inhibitors (11,12). Nevertheless, signaling events associated with DYRK1A-regulated drug resistance remain to be further exploited. A previous study revealed that DYRK1 could phosphorylate inhibitor of DNA binding 2 (ID2) on Thr27 and promote the ubiquitylation of HIF-2 $\alpha$ under normoxic conditions, whereas under hypoxic conditions, DYRK1 inactivation attenuated phosphorylation in glioblastoma cells (13). The present study aimed to investigate whether DYRK1A could affect HIF-1 $\alpha$ degradation and/or regulate HIF-1 $\alpha$ expression through STAT3 in liver cancer cells under hypoxic conditions.

Sorafenib and regorafenib are commonly used to treat patients with liver cancer; however, this is often with no satisfactory benefits (14). The activity of sorafenib and regorafenib is limited owing to primary and acquired resistance mechanisms. In addition, the resistance to these drugs is associated with the increased expression levels of multidrug resistance protein 1 , glucose transporter 1 and VEGF, owing to the stabilization of HIF-1 $\alpha$ protein $(15,16)$. Therefore, the present study aimed to investigate whether DYRK1A downregulation could affect the anti-liver cancer effect of regorafenib and sorafenib through the regulation of HIF-1 $\alpha$, thus providing a novel strategy for improving the clinical efficacy of regorafenib and sorafenib in the treatment of patients with liver cancer.

\section{Materials and methods}

Materials. Regorafenib (cat. no. A8236; 98.24\% purity) and sorafenib (cat. no. A3009; 99.87\% purity) were purchased from APeXBIO Technology LLC. Harmine (cat. no. HY-N0737A; $\geq 95 \%$ purity) was provided by MedChemExpress. The chemical structures of harmine, regorafenib and sorafenib were shown in Fig. 1. Cycloheximide (CHX, cat. no. 01810; $\geq 95 \%$ purity) was obtained from Sigma-Aldrich (Merck KGaA), and $20 \mu \mathrm{g} / \mathrm{ml} \mathrm{CHX}$ was used to prevent the synthesis of new proteins. DMSO was obtained from Hangzhou Keyi Biotechnology Co., Ltd., and the concentrations of DMSO used in the cell treatment were not exceed $0.1 \%$ to avoid little or no cytotoxicity. Anti-cleaved-caspase-3 (cat. no. 9661S; 1:1,000 dilution), anti-cleaved poly(ADP-ribose) polymerase (PARP) (cat. no. 9541S; 1:1,000 dilution), anti-DYRK1A (cat. no. 2771S; 1:1,000 dilution) and anti-myeloid cell leukemia-1 (Mcl-1; cat. no. 94296; 1:1,000 dilution) antibodies were obtained from Cell Signaling Technology, Inc. Anti-caspase-3 (cat. no. sc-7148; 1:500 dilution), anti-phosphorylated (p)-AKT (Ser473) (cat. no. sc-7985; 1:500 dilution), anti-STAT3 (cat. no. sc-482; $1: 500$ dilution) and anti- $\beta$-actin (cat. no. sc-47778; 1:500 dilution) antibodies were obtained from Santa Cruz
Biotechnology, Inc. Anti- $\alpha$-tubulin (cat. no. AF0001; 1:1,000 dilution) antibody was obtained from Beyotime Institute of Biotechnology. Anti-p-STAT3 (Tyr705) (cat. no. ab76315; 1:1,000 dilution) antibody was purchased from Abcam. Anti-HIF-1 $\alpha$ (cat. no. 610959; 1:1,000 dilution) and anti-AKT (cat. no. 610836; 1:1,000 dilution) antibodies were obtained from BD Biosciences.

Cell culture. 293T, HepG2, Hep3B and HuH7 were purchased from Shanghai Institute of Biochemistry and Cell Biology. Hep3B cells were maintained in Minimum Essential Medium (cat. no. 41500034; HyClone) supplemented with $10 \%$ FBS (cat. no. P30-3302, PAN-Biotech). HepG2 and HuH7 cells were maintained in DMEM (cat. no. C0006; Hangzhou Keyi Biotechnology Co., Ltd.) supplemented with 10\% FBS. 293T cells were cultured in 90\% DMEM supplemented with $10 \%$ FBS. The hypoxic condition was created by placing liver cancer cells in a sealed hypoxic chamber and equilibrating it with a gas mixture of $1 \% \mathrm{O}_{2}, 5 \% \mathrm{CO}_{2}$ and $94 \% \mathrm{~N}_{2}$. To prevent mycoplasma contamination, mycoplasma testing was performed for the cell lines used. Mycoplasma testing was performed on cell lines, which were then authenticated for genotypes using short tandem repeat DNA fingerprinting; the cells were passaged for $<6$ months (17).

Sulforhodamine $B$ (SRB) assay. HepG2, Hep3B and $\mathrm{HuH7}$ cells were seeded into a 96-well plate at a density of $8 \times 10^{3}$ cells/well. At $30 \%$ confluence, cells were incubated with 4-32 $\mu \mathrm{M}$ harmine, $0.25-8 \mu \mathrm{M}$ regorafenib and/or $2.5-20 \mu \mathrm{M}$ at $37^{\circ} \mathrm{C}$. Following incubation for $72 \mathrm{~h}$, cells were fixed with $10 \%$ trichloroacetic acid for $4 \mathrm{~h}$ at $4^{\circ} \mathrm{C}$, after which the 96 -well plate was washed with tap water. After the wells had dried, cells were stained with $0.4 \%$ SRB solution for $30 \mathrm{~min}$ at room temperature. Subsequently, cells were washed with $1 \%$ acetic acid. After the plates were dried up, $50 \mu \mathrm{l} \mathrm{SRB}$ dye was solubilized in Tris-based solution $(10 \mathrm{mM})$ at room temperature for 1 min. Finally, to determine cell cytotoxicity, the absorbance at a wavelength of $515 \mathrm{~nm}$ was measured in each well (18). Cell viability was calculated according to the following equation: Cell viability $=$ cell count of treated sample/cell count of control.

Colony formation assay. HepG2 and Hep3B cells were plated into culture dishes at a density of $6 \times 10^{3}$ cells/dish and were then treated with the $5,10,20$ or $40 \mu \mathrm{M}$ harmine, $4 \mu \mathrm{M}$ regorafenib and $2 \mu \mathrm{M}$ sorafenib for 14 days at $37^{\circ} \mathrm{C}$. The medium containing the compounds was replaced every 3 days. Following incubation for 14 days at $37^{\circ} \mathrm{C}$, cells were incubated with $0.1 \%$ crystal violet containing $1 \%$ methanol for $30 \mathrm{~min}$ at room temperature cells were then washed with PBS, as previously described (19). Colonies containing $>50$ cells were viewed by light microscope (x40 magnification) and counted using ImageJ software (National Institutes of Health; version v1.8.0).

Cell death detection. HepG2 and Hep3B cells were seeded into a six-well plate at a density of $2 \times 10^{4}$ cells/well. When cell confluence reached $\sim 30 \%$, as determined by light microscopy, they were treated with the 5 or $8 \mu \mathrm{M}$ harmine and/or 14 or $16 \mu \mathrm{M}$ regorafenib for $48 \mathrm{~h}$ at $37^{\circ} \mathrm{C}$. Subsequently, cells were collected at $448 \mathrm{x} \mathrm{g}$ for $5 \mathrm{~min}$ at room temperature and 
<smiles>COc1ccc2c(c1)[nH]c1c(C)nccc12</smiles>

Harmine<smiles>CNC(=O)c1cc(Oc2ccc(NC(=O)Nc3ccc(Cl)c(C(F)(F)F)c3)c(F)c2)ccn1</smiles>

Regorafenib

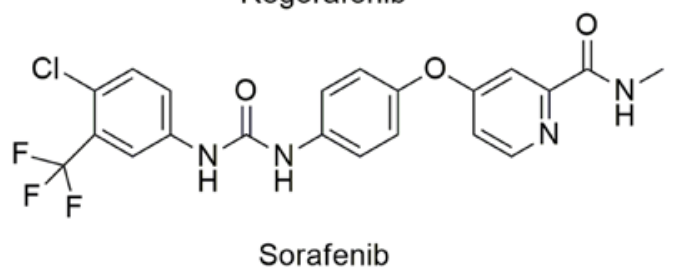

Figure 1. Chemical structures of harmine, regorafenib and sorafenib.

fixed with pre-cold $75 \%$ ethanol at $4^{\circ} \mathrm{C}$ for $2 \mathrm{~h}$ followed by treatment with $400 \mu \mathrm{l}$ PBS containing $50 \mu \mathrm{g} / \mathrm{ml}$ RNase A for $30 \mathrm{~min}$ at $37^{\circ} \mathrm{C}$. Subsequently, liver cancer cells were incubated with $5 \mu \mathrm{l}$ PI solution for $15 \mathrm{~min}$ at room temperature and were then analyzed using FACSCalibur flow cytometer, as previously described (17).

Western blot analysis. Liver cancer cells were collected, then incubated with lysis buffer (cat. no. P0013; Beyotime Institute of Biotechnology) on ice for $30 \mathrm{~min}$. The protein concentrations were determined by the BCA method using Enhanced BCA Protein Assay kit (cat. no. P0009; Beyotime Institute of Biotechnology). Proteins $(40 \mu \mathrm{g})$ were separated by SDS-PAGE on $8-12 \%$ Tris-glycine gels. Following electrophoresis, the proteins were transferred to PVDF membranes, which were then blocked with $5 \%$ skimmed milk for $2 \mathrm{~h}$ at room temperature followed by washing with TBS $+0.1 \%$ Tween-20 (TBST) three times. Following incubation with primary antibodies overnight at $4^{\circ} \mathrm{C}$, the membranes were washed thrice with TBST and then incubated with the corresponding secondary antibodies (DyLight ${ }^{\mathrm{TM}} 800$ 4X PEG-conjugated anti-rabbit-IgG; DyLight ${ }^{\mathrm{TM}} 800$ 4X PEG-conjugated anti-mouse-IgG; 1:50,000; Cell Signaling Technology) for $2 \mathrm{~h}$ at room temperature. Finally, after washing three times with TBST, 5 min each, the bands were visualized using an LiCor Odyssey CLx imager and Odyssey CLX Image Studio software version 5.0.21 (LI-COR Biosciences) (17). ImageJ (version: 1.52a; National Institutes of Health) was used to semi-quantitatively analyze protein expression levels.

Reverse transcription-quantitative PCR (RT-qPCR). Total RNA was extracted from liver cancer cells using TRIzol ${ }^{\circledR}$ reagent (Invitrogen; Thermo Fisher Scientific, Inc.), precipitated with isopropyl alcohol and rinsed with $70 \%$ ethanol. Subsequently, total RNA was reverse transcribed into cDNA using the iScript cDNA Synthesis kit according to the manufacturer's protocol (Bio-Rad Laboratories, Inc.). qPCR was then performed using an iQ SYBR-Green Supermix (cat. no. 1708880; Bio-Rad Laboratories, Inc.) according to the manufacturer's protocol. Thermocycling conditions were as follows: Initial denaturation of $15 \mathrm{~min}$ at $95^{\circ} \mathrm{C}$; followed by 40 cycles of denaturation at $94^{\circ} \mathrm{C}$ for $30 \mathrm{sec}$, annealing at $56^{\circ} \mathrm{C}$ for $30 \mathrm{sec}$ and extension at $72^{\circ} \mathrm{C}$ for $30 \mathrm{sec}$; with a final extension at $72^{\circ} \mathrm{C}$ for $5 \mathrm{~min}$. The $2^{-\Delta \Delta \mathrm{CQ}}$ method was used to analyzed the mRNA levels of indicated genes. The primers were as follows: DYRK1A forward, 5'-TCTGGGTATTCC ACCTGCTC-3' and reverse, 5'-GTCCTCCTGTTTCCACTC CA-3'; HIF-1 $\alpha$ forward, 5'-ATCCATGTGACCATGAGGAAA TG-3' and reverse, 5'-TCGGCTAGTTAGGGTACACTTC-3'; and GAPDH forward, 5'-GAGTCAACGGATTTGGTCGT-3' and reverse, 5'-TTGATTTTGGAGGGATCTCG-3'.

Co-immunoprecipitation (Co-IP) assay. For Co-IP assays, 293T cells overexpressing DYRK1A were lysed with IP buffer (cat. no. P0013; Beyotime Institute of Biotechnology) followed by centrifugation at $10,000 \mathrm{x}$ for $30 \mathrm{~min}$ at $4^{\circ} \mathrm{C}$. Subsequently, the cell lysates were incubated with $20 \mu \mathrm{l}$ protein $\mathrm{G}$ magnetic beads at $4^{\circ} \mathrm{C}$ for $1 \mathrm{~h}$. Each $\mathrm{Co}$-IP reaction was set up with equal quantities of lysate $(1,000 \mu \mathrm{g})$. The lysates were incubated with the anti-STAT3 antibody (cat. no. sc-7148; 1:200 dilution; Santa Cruz Biotechnology, Inc.) and overnight with gentle shaking at $4^{\circ} \mathrm{C}$. Following incubation, the lysates were centrifuged at 3,000 $\mathrm{g}$ for $5 \mathrm{~min}$ at $4^{\circ} \mathrm{C}$. Subsequently, the supernatant was carefully aspirated and the protein $\mathrm{G}$ magnetic beads were washed 3-4 times with lysis buffer, supplemented with SDS loading buffer and subjected to SDS-PAGE, as previously described (20).

Plasmid and small interfering RNA (siRNA) transfection. HepG2, Hep3B and HuH7 cells were seeded into six-well plates at a density of $3 \times 10^{5}$ cells/well. When reaching $30 \%$ confluence, cells were transfected with overexpression plasmids or siRNA using the jetPRIME reagent (Polyplus-transfection SA) according to the manufacturer's instructions. siRNAs against human DYRK1A and HIF-1 $\alpha$ were synthesized by Shanghai GenePharma Co., Ltd. (20). The sense sequences of human siRNAs were as follows: siDYRK1A-1, 5'-AUGGAGCUA UGGACGUUAATT-3'; siDYRK1A-2, 5'-AAACUCGAA UUCAACCUUATT-3'; siHIF-1 $\alpha-1,5$ '-CUGAUGACCAGC AACUUGATT-3'; siHIF-1 $\alpha-2,5$-AUCCAGAGUCACUGG AACUTT-3'; and negative control siRNA (siNC), 5'-UUC UCCGAACGUGUCACGUTT-3'. The plasmid pcDNA3.1 containing the insert DYRK1A and empty vector pcDNA3.1 were purchased from GenScript. After $24 \mathrm{~h}$ siRNA transfection, the cells were treated with $2.5-20 \mu \mathrm{M}$ sorafenib and/or $0.25-8 \mu \mathrm{M}$ regorafenib (ranging from $0.25-8 \mu \mathrm{M}$ ) at $37^{\circ} \mathrm{C}$ for $72 \mathrm{~h}$. SRB was used to detect the cytotoxicity of cancer cells.

HIF-1 $\alpha$ accumulation detection. HepG2 cells were pretreated with $20 \mu \mathrm{g} / \mathrm{ml} \mathrm{CHX}$ under normoxic conditions for $4 \mathrm{~h}$ to inhibit synthesis of new proteins and HIF-1 $\alpha$ degradation. The CHX-pretreated cells were then cultivated in fresh medium and cultured under hypoxic conditions to detect the accumulation of HIF-1 $\alpha$ using western blot.

Bioinformatics analysis. The co-expressed genes of DYRK1A in the TCGA database were examined by cBioPortal (www. cbioportal.org). The study 'Liver Hepatocellular Carcinoma 
A

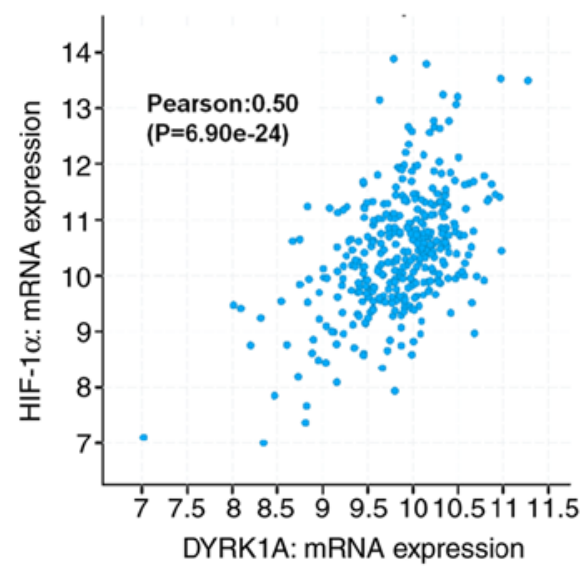

B

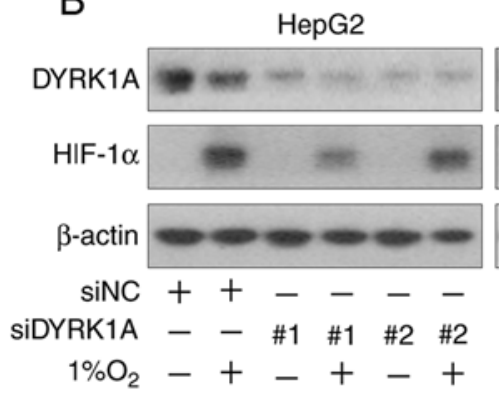

$\mathrm{D}$

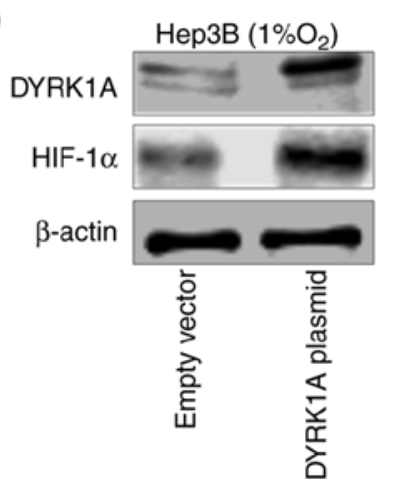

Нер3B

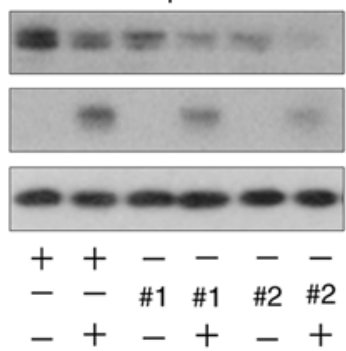

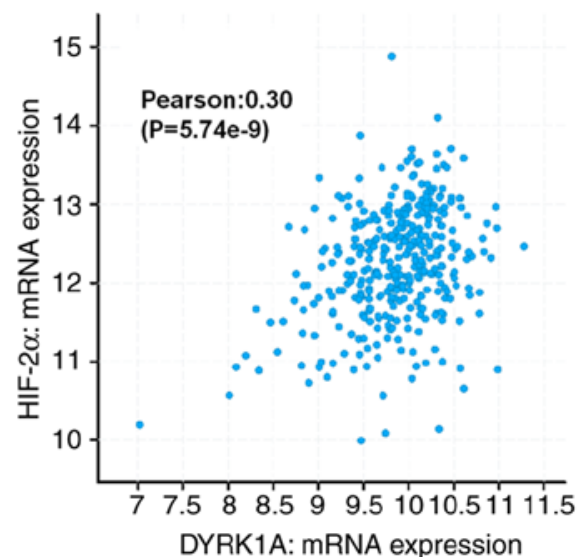

C

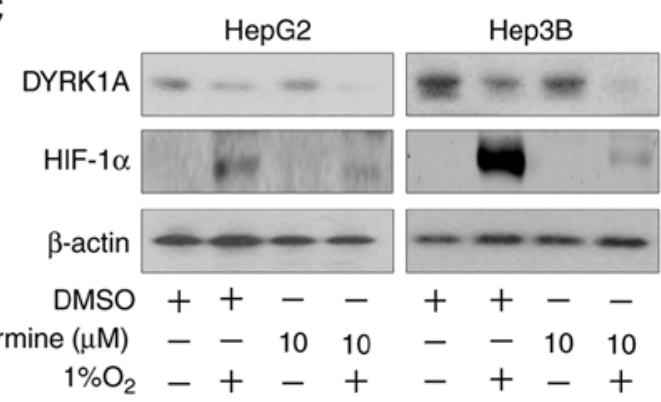

$\mathrm{F}$

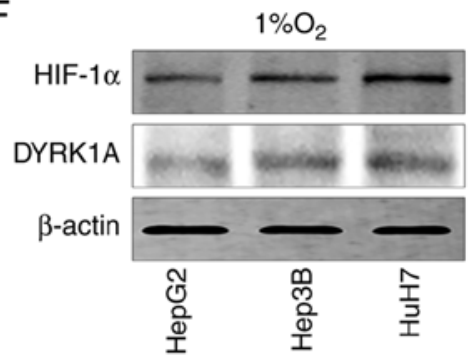

Figure 2. DYRK1A positively regulates HIF-1 $\alpha$ in liver cancer cells under hypoxic conditions. (A) Co-expression analysis of DYRK1A and HIF-1 $\alpha$ (left panel) or DYRK1A and HIF-2 $\alpha$ (right panel) were conducted using cBioPortal in liver cancer. (B) Western blot analysis of the protein expression levels of DYRK1A and HIF-1 $\alpha$ in HepG2 and Hep3B cell lines transfected with siDYRK1A-1 or siDYRK1A-2 for $48 \mathrm{~h}$ and cultured under either hypoxic or normoxic conditions for $6 \mathrm{~h}$. (C) Western blot analysis of the protein expression levels of DYRK1A and HIF-1 $\alpha$ in HepG2 and Hep3B cell lines treated with $10 \mu \mathrm{M}$ harmine for $24 \mathrm{~h}$ and then exposed to normoxic or hypoxic conditions for $6 \mathrm{~h}$. (D) Western blot analysis of the protein expression levels of DYRK1A and HIF-1 $\alpha$ in Hep3B cells transfected with DYRK1A overexpression plasmid or empty vector for $48 \mathrm{~h}$ and then cultured under hypoxic conditions for an additional $6 \mathrm{~h}$. (E) Western blot analysis of the protein expression levels of DYRK1A and HIF- $1 \alpha$ in Hep3B cells transfected with siHIF-1 $\alpha$ and siNC for $48 \mathrm{~h}$ and then cultured under hypoxic conditions for $6 \mathrm{~h}$. (F) Western blot analysis of the protein expression levels of DYRK1A and HIF-1 $\alpha$ in HepG2, Hep3B and HuH7 cells cultured under hypoxic conditions for $6 \mathrm{~h}$. DYRK1A, dual-specificity tyrosine-phosphorylation-regulated kinase 1A; HIF, hypoxia inducible factor; NC, negative control; si, small interfering RNA; TCGA, The Cancer Genome Atlas.

(TCGA, Provisional)' ( $\mathrm{n}=442$ ) was selected to evaluate Pearson's correlation coefficient between the expression of DYRK1A and HIF-1 $\alpha$ or DYRK1A and HIF- $2 \alpha$ in liver cancer $(17,18)$.

Statistical analysis. All experiments were conducted at least three times. All data are presented as the mean \pm SD. A two-tailed unpaired Student's t-test was used to determine the differences between two groups. One-way ANOVA followed by Tukey's post hoc test was used to examine the differences among multiple groups. Statistical analyses were performed using GraphPad Prism version 7 (GraphPad Software, Inc.).
$\mathrm{P}<0.05$ was considered to indicate a statistically significant difference. The combination index (CI) was calculated using CalcuSyn software (version 2.0; Biosoft). The CI value indicated the interaction of the treatment combination as follows: $\mathrm{CI}<0.9$, synergism; 0.9-1.10, additive; and $>1.10$, antagonism.

\section{Results}

DYRK1A positively regulates HIF-1 $\alpha$ in liver cancer cells under hypoxic conditions. As shown in Fig. 2A, the expression levels of DYRK1A in liver cancer were positively correlated with those of HIF-1 $\alpha$ (Pearson's correlation test, $r=0.50$; 
A

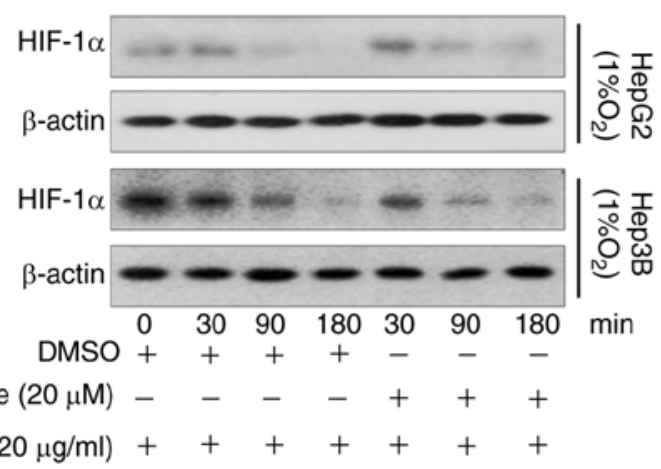

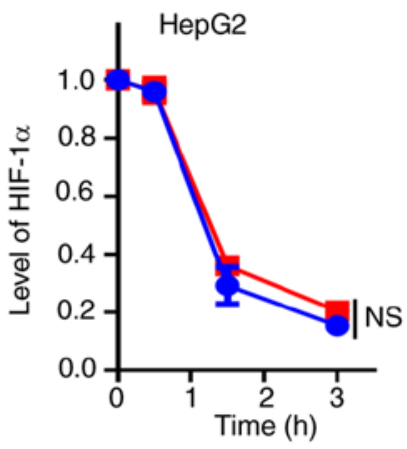

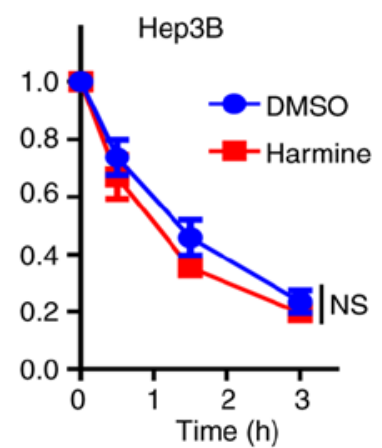

B

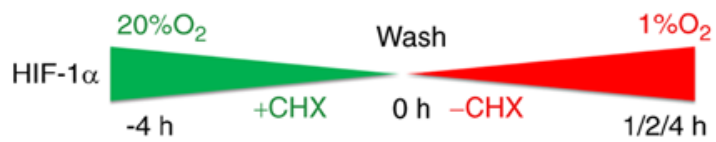

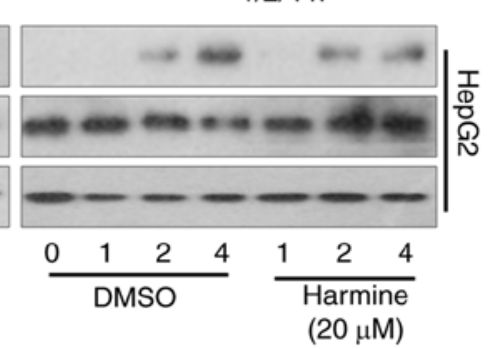

C

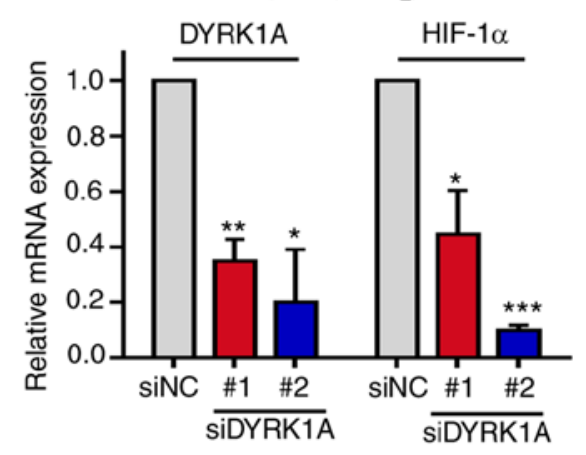

D

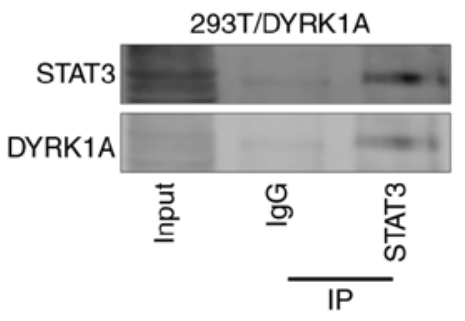

E
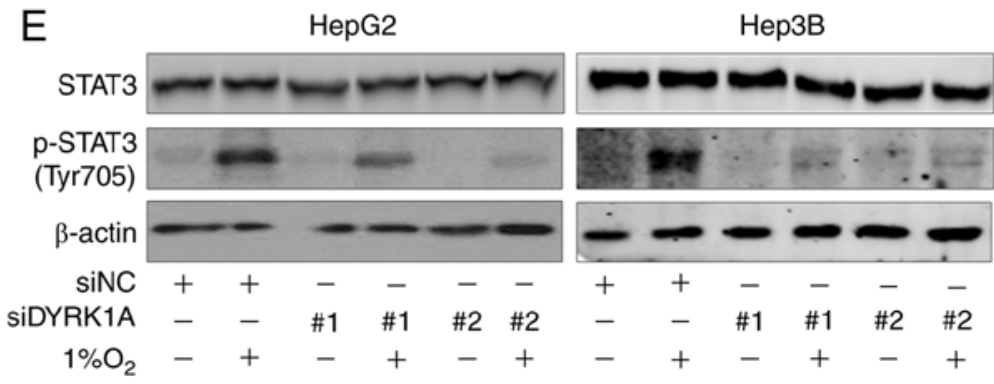

$\mathrm{F}$

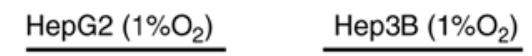

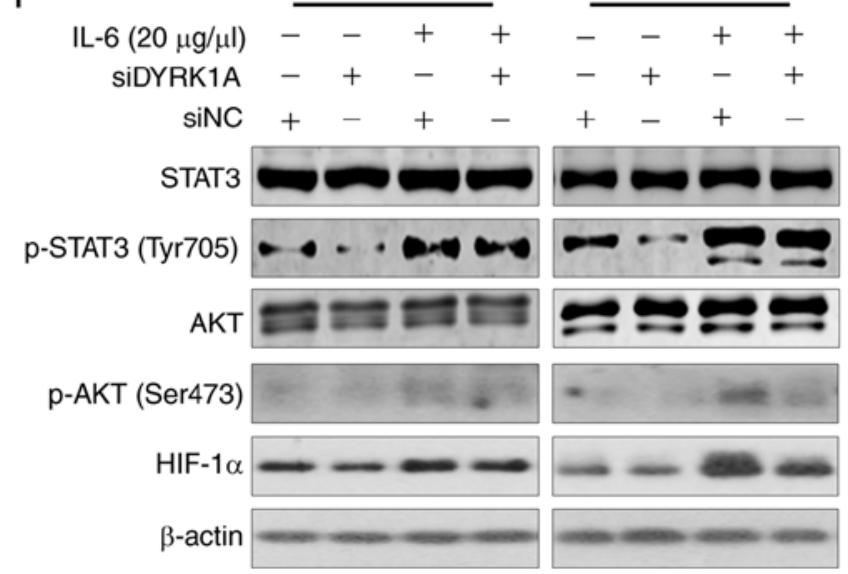

$-++$

$-+-+$

$+\quad+\quad-$

Figure 3. DYRK1A regulates the expression of HIF-1 $\alpha$ via STAT3 signaling in liver cancer cells. (A) Western blot analysis of the protein expression levels of HIF-1 $\alpha$ in HepG2 and Hep3B cell lines treated with $20 \mu \mathrm{g} / \mathrm{ml} \mathrm{CHX}$ with or without $10 \mu \mathrm{M}$ harmine for 30,90 or $180 \mathrm{~min}$. A two-tailed unpaired Student's t-test was used to determine the differences between DMSO-treated group and harmine-treated group. (B) HepG2 cells pretreated with $\mathrm{CHX}$ for $4 \mathrm{~h}$ were co-treated with the indicated siRNA clones for $48 \mathrm{~h}$ under normoxic conditions. Subsequently, cells were cultured in new medium and treated with or without harmine for the indicated time points under hypoxic conditions. Western blot analysis was used to detect the protein expression levels of DYRK1A and HIF-1 $\alpha$. (C) Reverse transcription-quantitative PCR analysis of DYRK1A and HIF-1 $\alpha$ mRNA expression levels in HepG2 cells transfected with the indicated siRNA clones for $48 \mathrm{~h}$. A two-tailed unpaired Student's t-test was used to determine the differences between DYRK1A siRNA and siNC. ${ }^{*} \mathrm{P}<0.05,{ }^{* *} \mathrm{P}<0.01$ and ${ }^{* * *} \mathrm{P}<0.001$. (D) Co-immunoprecipitation analysis of the interaction between DYRK1A and STAT3 in 293T cells transfected with DYRK1A overexpression plasmid for $48 \mathrm{~h}$. (E) Western blot analysis of the protein expression levels of STAT3 and p-STAT3 (Tyr705) in HepG2 and Hep3B cell lines treated with the indicated siRNA clones for $48 \mathrm{~h}$ and then cultured under normoxic or hypoxic conditions for $6 \mathrm{~h}$. (F) Following transfection for $48 \mathrm{~h}$, liver cancer cells were treated with or without $20 \mu \mathrm{g} / \mu 1 \mathrm{IL}-6$ for $1 \mathrm{~h}$. The expression levels of the associated proteins, including STAT3, p-STAT3 (Tyr705), AKT, p-AKT(Ser473), and HIF-1 $\alpha$, were detected by western blot analysis. CHX, cycloheximide; DYRK1A, dual-specificity tyrosine-phosphorylation-regulated kinase $1 \mathrm{~A}$; HIF-1 $\alpha$, hypoxia inducible factor-1 $\alpha$; NS, not significant; $p$, phosphorylated; si, small interfering RNA. 

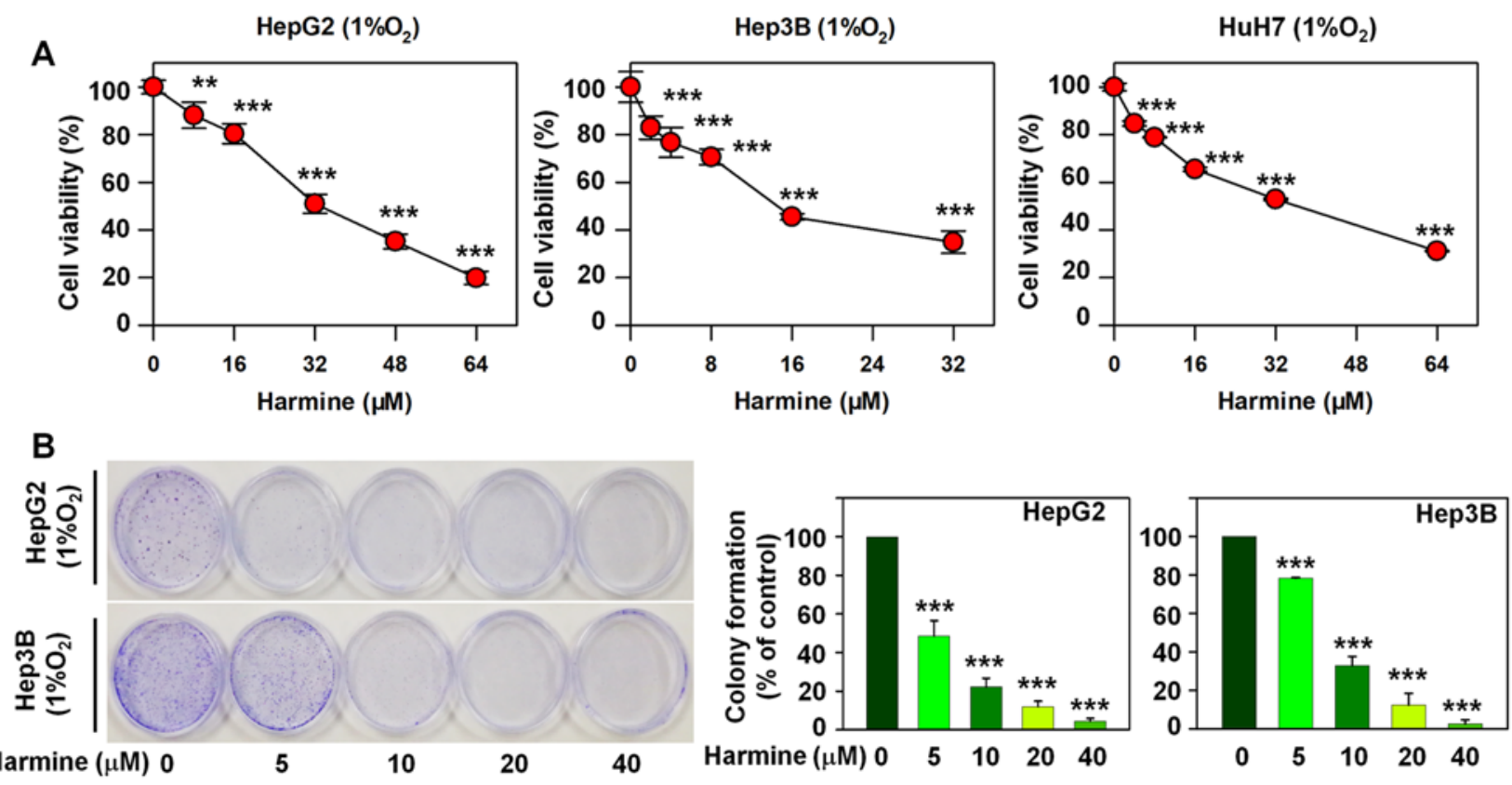

Figure 4. Harmine decreases liver cancer cell proliferation under hypoxic conditions. (A) SRB analysis of the cell viability of HepG2, Hep3B, and HuH7 cells treated with harmine for $72 \mathrm{~h}$ under hypoxic conditions. One-way ANOVA followed by Tukey's post hoc test was used to examine the significant differences among multiple groups. ${ }^{* *} \mathrm{P}<0.01,{ }^{* * *} \mathrm{P}<0.001$ vs. negative control $(0 \mu \mathrm{M})$. (B) Colony formation analysis to determine proliferation of HepG2 and Hep3B cells treated with the indicated concentrations of harmine for 14 days under hypoxic conditions. One-way ANOVA followed by Tukey's post hoc test was used to examine the significant differences among multiple groups. ${ }^{* * *} \mathrm{P}<0.001$ vs. negative control $(0 \mu \mathrm{M})$.

$\left.\mathrm{P}=6.63 \times 10^{-24}\right)$ as well as HIF-2 $\alpha$ (Pearson's correlation test, $\mathrm{r}=0.30$ and $\left.\mathrm{P}=5.74 \times 10^{-9}\right)(17)$. These results were collected from cBioPortal and suggested that DYRK1A expression exhibited a stronger positive correlation with HIF-1 $\alpha$ expression compared the correlation between DYRK1A and HIF- $2 \alpha$ in liver cancer, indicated that DYRK1A co-expressed with HIF-1 $\alpha$ in liver cancer patients.

Furthermore, the in vitro transfection results revealed that HIF-1 $\alpha$ protein expression was markedly increased in the siNC group under hypoxia compared with normoxia. However, the protein expression levels of HIF-1 $\alpha$ were notably reduced in the DYRK1A knockdown group compared with siNC group under hypoxia (Fig. 2B). Additionally, cell treatment with the DYRK1A inhibitor harmine downregulated HIF-1 $\alpha$ in liver cancer cells under hypoxia (Fig. 2C). Conversely, DYRK1A overexpression in liver cancer cells notably upregulated HIF-1 $\alpha$ compared with empty vector group under hypoxia (Fig. 2D). However, HIF-1 $\alpha$ silencing did not affect the expression of DYRK1A in liver cancer cells under hypoxia (Fig. 2E). Furthermore, liver cancer cell lines overexpressing DYRK1A exhibited upregulated expression of HIF-1 $\alpha$ under hypoxia (Fig. 2F). The aforementioned findings indicated that DYRK1A could be a potential upstream activator of HIF-1 $\alpha$ in liver cancer cells.

DYRK $1 A$ regulates the expression of $H I F-1 \alpha$. The underlying mechanisms of DYRK1A on the regulation of HIF-1 $\alpha$ expression under hypoxic conditions was investigated next. The degradation rate of HIF-1 $\alpha$ was compared in harmineor DMSO-treated liver cancer cells co-treated with $\mathrm{CHX}$. The results demonstrated that there was no difference in the degradation rate of HIF-1 $\alpha$ between cells treated with or without harmine, thus suggesting that DYRK1A may not act on HIF-1 $\alpha$ degradation (Fig. 3A). As demonstrated in Fig. 3B, DYRK1A knockdown or treatment with harmine suppressed the accumulation of HIF-1 $\alpha$ in liver cancer cells under hypoxia. Furthermore, DYRK1A knockdown downregulated HIF-1 $\alpha$ mRNA expression levels in HepG2 cells (Fig. 3C). These data suggested that DYRK1A may regulate the expression of HIF-1 $\alpha$ in liver cancer cells.

DYRK $1 A$ regulates the expression of HIF-1 $\alpha$ via STAT3 signaling. STAT3 directly binds to the HIF-1 $\alpha$ gene promoter to transcriptionally regulate its expression (20). Co-IP results indicated that DYRK1A may directly interact with STAT3 (Fig. 3D). Furthermore, DYRK1A knockdown reversed the hypoxia-induced activation of STAT3 compared with control siRNA group (Fig. 3E). Additionally, the IL-6-induced phosphorylation of STAT3 and AKT expression was attenuated by DYRK1A depletion (Fig. 3F). These findings indicated that DYRK1A may regulate the expression of HIF-1 $\alpha$ via the STAT3 signaling pathway.

DYRK1A knockdown inhibits the regorafenib-mediated liver cancer cell viability under hypoxia. We hypothesized that suppressing DYRK1A expression may be a novel strategy for overcoming drug resistance in liver cancer treatment. As shown in Fig. 4A and B, harmine inhibited the viability of liver cancer cells in a dose-dependent manner under hypoxic conditions.

Sorafenib and regorafenib are the recommended first- and second-line therapies for patients with advanced liver cancer, respectively, and the Food and Drug Administration (FDA) has approved regorafenib for treating patients with liver cancer who progress after sorafenib failure $(21,22)$. We hypothesized that DYRK1A may regulate the expression of HIF-1 $\alpha$ and 
A

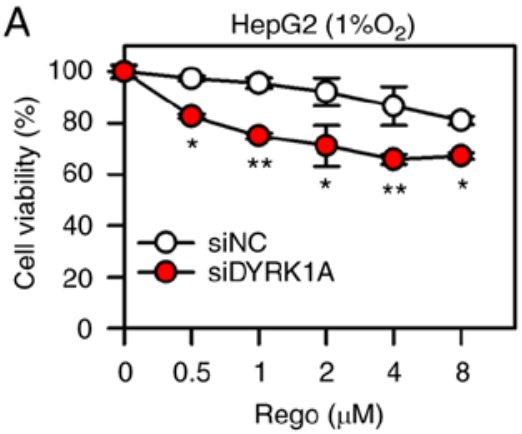

B

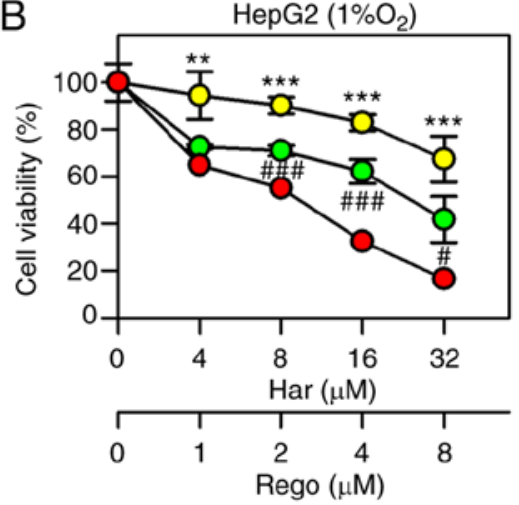

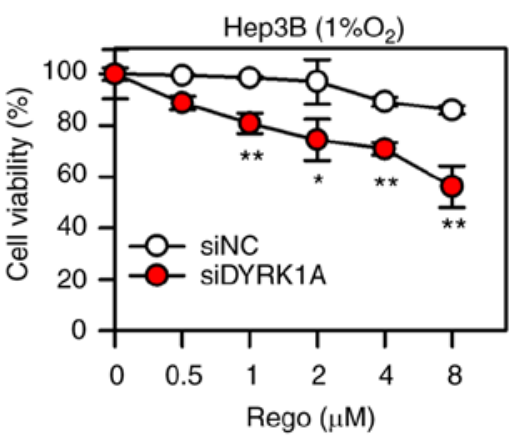

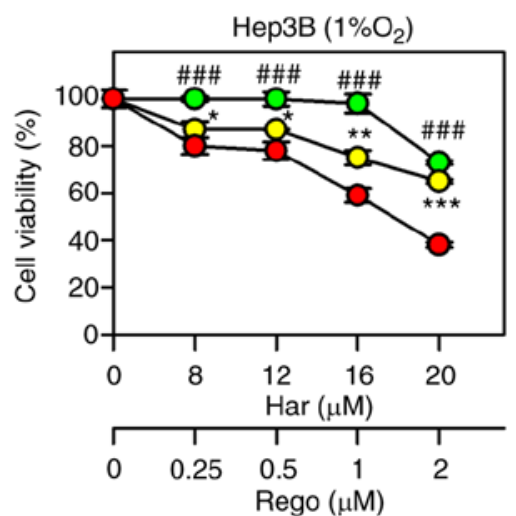

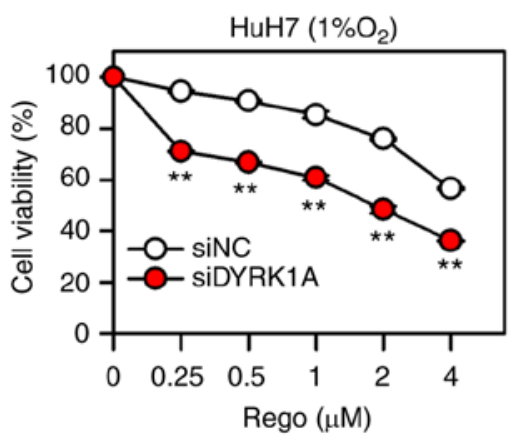

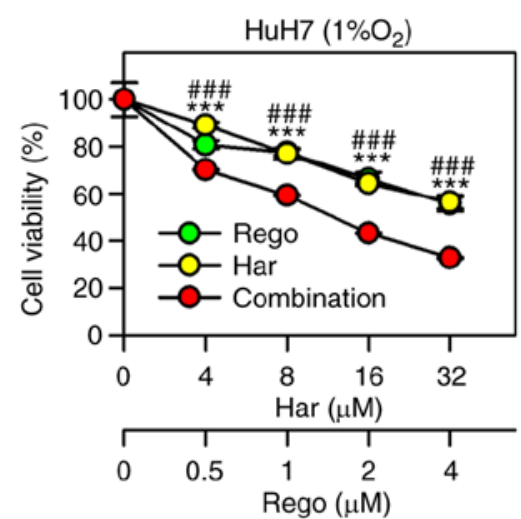

C

\begin{tabular}{ccccccccccc}
\hline & HepG2 & \multicolumn{3}{c}{ Hep3B } & \multicolumn{3}{c}{ HuH7 } \\
\hline Rego $(\mu \mathrm{M})$ & Har $(\mu \mathrm{M})$ & CI values & $\operatorname{Rego}(\mu \mathrm{M})$ & $\operatorname{Har}(\mu \mathrm{M})$ & CI values & $\operatorname{Rego}(\mu \mathrm{M})$ & Har $(\mu \mathrm{M})$ & CI values \\
\hline 1 & 4 & 0.52 & 0.25 & 8 & 0.49 & 0.5 & 4 & 0.70 \\
2 & 8 & 0.57 & 0.5 & 12 & 0.86 & 1 & 8 & 0.76 \\
4 & 16 & 0.30 & 1 & 16 & 0.73 & 2 & 16 & 0.67 \\
8 & 32 & 0.18 & 2 & 20 & 0.85 & 4 & 32 & 0.77 \\
\hline
\end{tabular}

Figure 5. DYRK1A knockdown enhances the anti-proliferative effects of Rego on liver cancer cells under hypoxic conditions. (A) SRB analysis of the viability of HepG2, Hep3B and HuH7 cells transfected with the indicated siRNA clones for $24 \mathrm{~h}$ and then exposed to the indicated concentrations of Rego under hypoxic conditions for $72 \mathrm{~h}$. A two-tailed unpaired Student's t-test was used to determine the differences between siDYRK1A and negative control siRNA at each concentration. ${ }^{*} \mathrm{P}<0.05,{ }^{* *} \mathrm{P}<0.01$. (B) SRB analysis of the viability of HepG2, Hep3B and HuH7 cells treated with the indicated concentrations of Har and/or Rego for $72 \mathrm{~h}$ under hypoxic conditions. One-way ANOVA followed by Tukey's post hoc test was used to examine the significant differences among multiple groups. ${ }^{*} \mathrm{P}<0.05,{ }^{* *} \mathrm{P}<0.01,{ }^{* * *} \mathrm{P}<0.001$ Har vs. combination; ${ }^{\#} \mathrm{P}<0.05,{ }^{\# \# \#} \mathrm{P}<0.001$ Rego vs. combination. (C) The CI values were calculated to determine synergistic effects $(\mathrm{CI}<0.9)$. CI, combination index; DYRK1A, dual-specificity tyrosine-phosphorylation-regulated kinase 1A; Har, harmine; Rego, regorafenib; si, small interfering RNA.

be associated with resistance to sorafenib and regorafenib under hypoxic conditions. Under hypoxia, DYRK1A silencing significantly inhibited the viability of regorafenib-treated liver cancer cells (Fig. 5A). Furthermore, co-treatment of liver cancer cells with harmine and regorafenib exhibited synergistic anti-proliferative effects on liver cancer cells under hypoxia (Fig. 5B and C).

Harmine enhances the apoptotic effect of regorafenib on liver cancer cells under hypoxic conditions. To further verify the synergistic anti-liver cancer effect of harmine and regorafenib, PI staining was carried out to evaluate cell death. As demonstrated in Fig. 6A and B, under hypoxia, harmine plus regorafenib enhanced the apoptotic effect compared with harmine or regorafenib alone treatment on HepG2 and Hep3B cells. In addition, western blot analysis was performed to detect the expression levels of apoptosis-related proteins, cleaved caspase 3 and cleaved PARP, and the results confirmed that under hypoxic conditions harmine treatment in combination with regorafenib notably promoted liver cancer cell apoptosis compared with harmine or regorafenib single agent treatment (Fig. 6C). Furthermore, harmine plus regorafenib treatment markedly downregulated $\mathrm{Mcl}-1$ protein expression levels compared with cell treatment with each agent alone, suggesting that the combination of harmine and regorafenib could induce apoptosis via the mitochondrial pathway. In addition, harmine combined with regorafenib markedly inhibited the protein expression levels HIF-1 $\alpha$ and the phosphorylation of STAT3 and AKT compared with harmine or regorafenib single agent treatment (Fig. 6D). Overall, these results indicated that harmine plus regorafenib may enhance liver cancer cell apoptosis under hypoxic conditions.

DYRK1A downregulation enhances the anti-liver cancer activity of sorafenib under hypoxia. As shown in Fig. 7A, DYRK1A knockdown decreased the viability of sorafenib-treated liver cancer cells compared with control siRNA group under hypoxic conditions. Furthermore, cell 
A
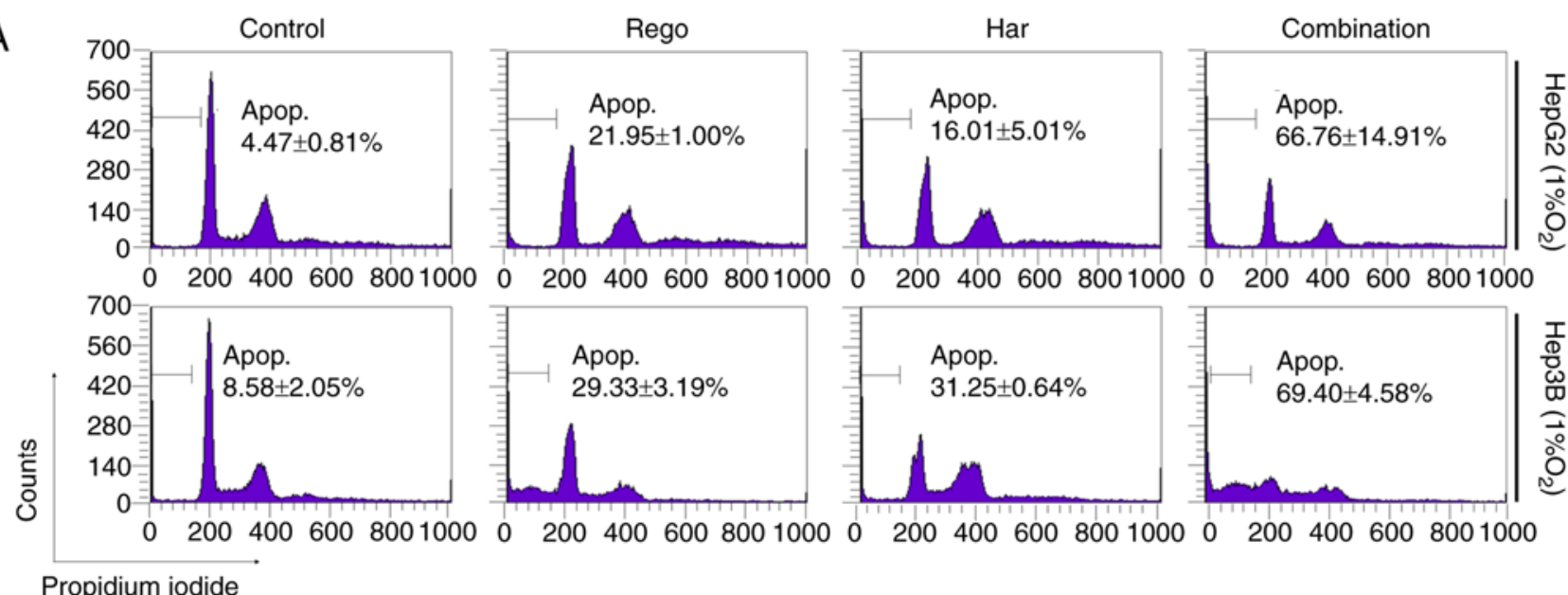

B

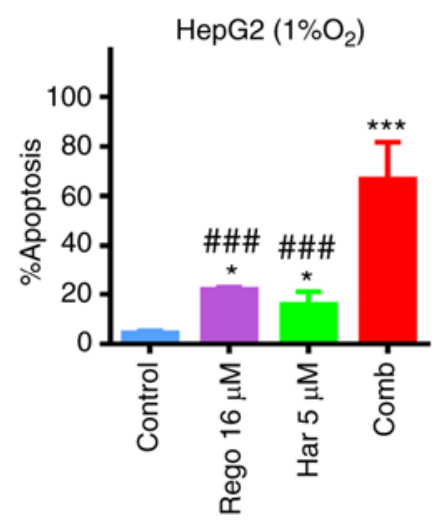

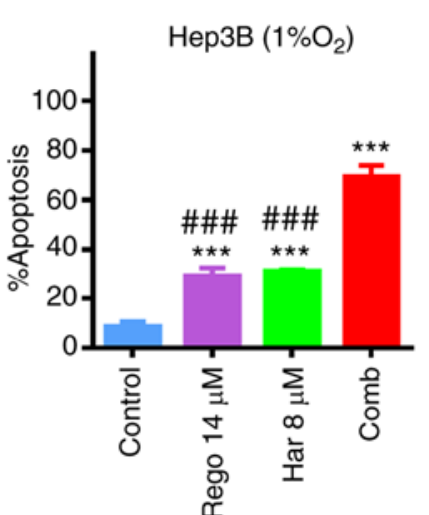

C

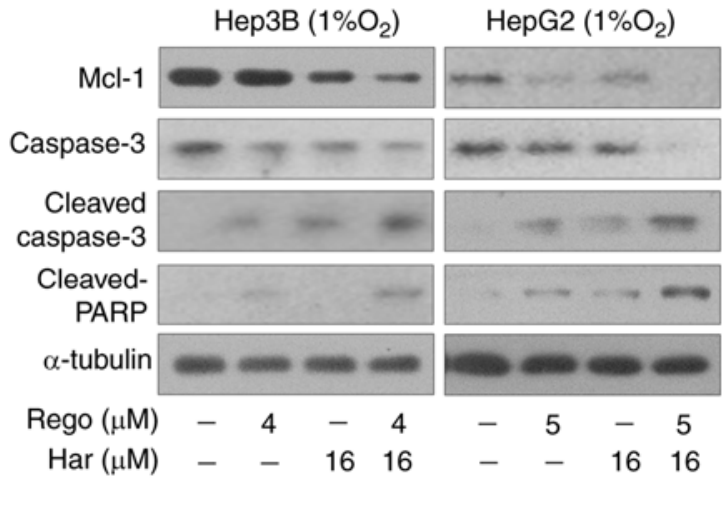

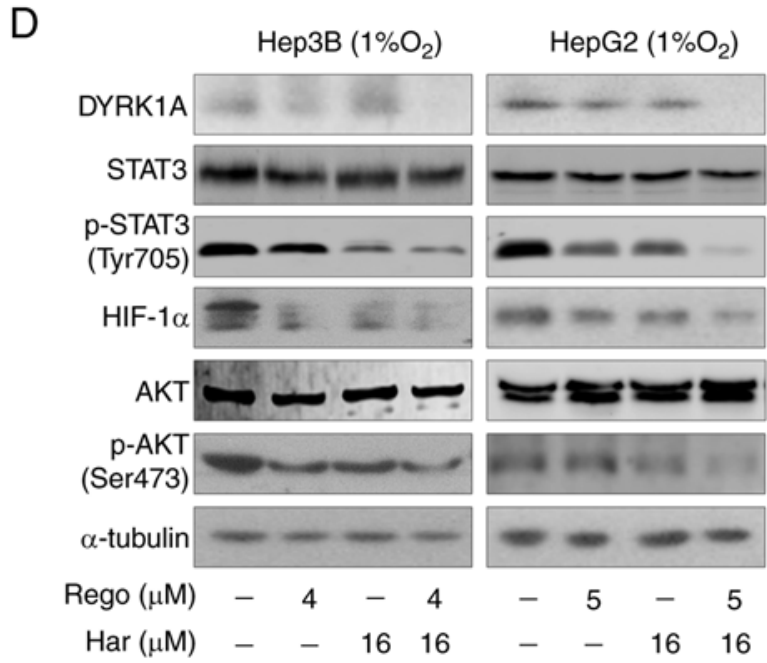

Figure 6. Under hypoxic conditions, Har enhances the apoptotic effect of Rego on liver cancer cells. (A and B) PI staining and flow cytometric analysis of the cell death of HepG2 and Hep3B cells treated with the indicated concentrations of Har and/or Rego for 48 h under hypoxia. One-way ANOVA followed by Tukey's post hoc test was used to examine the significant differences among multiple groups. ${ }^{*} \mathrm{P}<0.05$ vs. control, ${ }^{* * *} \mathrm{P}<0.001$ vs. control, ${ }^{\# \#} \mathrm{P}<0.001$ vs. combination. Western blot analysis of the protein expression levels of (C) Mcl-1, caspase-3, cleaved-caspase-3, and cleaved-PARP and (D) DYRK1A, STAT3, p-STAT3(Tyr705), HIF-1 $\alpha$, AKT, and p-AKT (ser473) in HepG2 and Hep3B cells treated with the indicated concentrations of Har and/or Rego for 48 h under hypoxic conditions. Apop, apoptosis; DYRK1A, dual-specificity tyrosine-phosphorylation-regulated kinase 1A; Har, harmine; HIF-1 $\alpha$, hypoxia inducible factor-1 $\alpha$; Mcl1, myeloid cell leukemia-1; p, phosphorylated; PARP, poly(ADP-ribose) polymerase; Rego, regorafenib.

co-treatment with harmine and sorafenib for $72 \mathrm{~h}$ significantly reduced the viability of liver cancer cells compared with cells treated with each agent alone (Fig. 7B). CI value analysis revealed that harmine may work synergistically with sorafenib under hypoxic culture conditions (CI<0.9; Fig. 7C). Furthermore, colony formation assays showed that treatment with harmine plus regorafenib enhanced the inhibition of liver cancer cell proliferation compared with harmine or regorafenib single agent alone under hypoxic conditions, the same phenomenon was also observed in harmine plus sorafenib combination treatment (Fig. 7D). In addition, co-treatment with harmine and sorafenib further promoted cell death in 
A

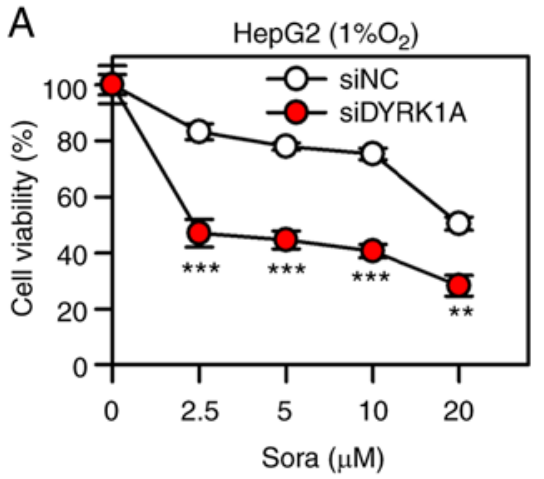

B

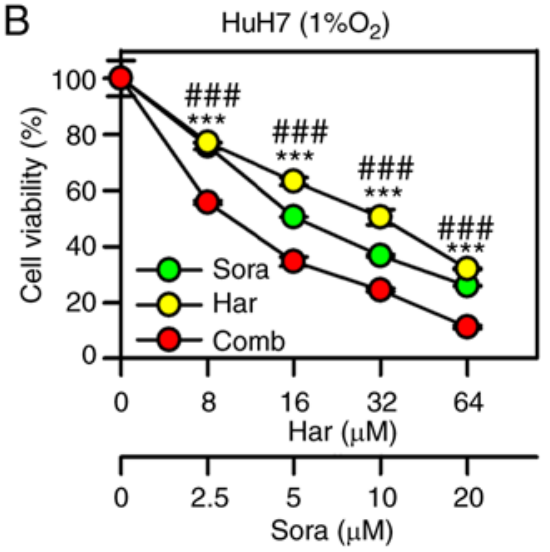

C

\begin{tabular}{c|c|c|}
\hline Sora $(\mu \mathrm{M})$ & $\operatorname{Har}(\mu \mathrm{M})$ & CI values \\
\hline 2.5 & 8 & 0.58 \\
5 & 16 & 0.80 \\
10 & 32 & 0.67 \\
20 & 64 & 0.85 \\
\hline
\end{tabular}

E
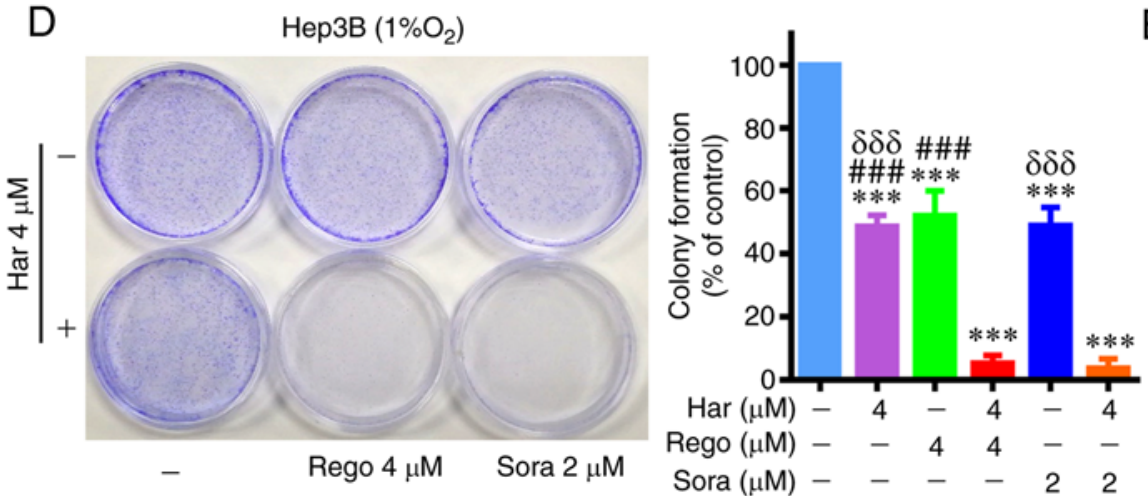

Figure 7. Harmine enhances the anticancer effects of Sora and Rego under hypoxic conditions. (A) SRB analysis of the viability of HepG2 cells transfected with the indicated siRNA clones for $24 \mathrm{~h}$ and then treated with various concentrations of Sora under hypoxic conditions for an additional $72 \mathrm{~h}$. A two-tailed unpaired Student's t-test was used to determine the differences between siDYRK1A and siNC at each concentration. ${ }^{* *} \mathrm{P}<0.01$ and ${ }^{* * *} \mathrm{P}<0.001$. (B) $\mathrm{SRB}$ analysis of the viability of $\mathrm{HuH} 7$ cells treated with the indicated concentrations of each compound for $72 \mathrm{~h}$ under hypoxic conditions. One-way ANOVA followed by Tukey's post hoc test was used to examine the significant differences among multiple groups. ${ }^{* * *} \mathrm{P}<0.001 \mathrm{Sora}$ vs. combination; ${ }^{\# \# \#} \mathrm{P}<0.001 \mathrm{Har}$ vs. combination. (C) The CI values were calculated to determine synergistic effects $(\mathrm{CI}<0.9)$. (D) Colony formation assay was used to measure the proliferation of Hep3B cells under hypoxic conditions after co-treatment with various combinations of Har, Rego and Sora. One-way ANOVA followed by Tukey's post hoc test was used to examine the significant differences among multiple groups. ${ }^{* * *} \mathrm{P}<0.001$ vs. negative control; ${ }^{\# \#} \mathrm{P}<0.001$ vs. Har $+\mathrm{Rego}$; ${ }^{\delta \delta \delta} \mathrm{P}<0.001 \mathrm{vs}$. Har $+\mathrm{Sora}$. (E) Western blot analysis of the protein expression levels of caspase-3 and cleaved-PARP in HepG2 cells treated with the indicated concentrations of harmine and/or sorafenib for $48 \mathrm{~h}$ under hypoxic conditions. CI, combination index; Har, harmine; PARP, poly(ADP-ribose) polymerase; Rego, regorafenib; si, small interfering RNA; Sora, sorafenib.

HepG2 cells, as indicated by the upregulated expression levels of cleaved PARP and the downregulated expression of caspase 3 (Fig. 7E). Collectively, these findings suggested that targeting DYRK1A could be an effective approach for preventing hypoxia-induced liver cancer progression and therapy resistance.

\section{Discussion}

DYRK1A serves a crucial role in cell growth and tumorigenesis; it exhibits both tumor suppressive and oncogenic activities, depending on the tissue (23). More specifically, DYRK1A acts as an oncogenic protein in liver cancer. For example, a previous study demonstrated that DYRK1A could interact with trophinin-associated protein and promote cell growth by activating AKT/glycogen synthase kinase-3 $\beta$ signaling (24), which suggested that targeting DYRKA may be a promising therapeutic strategy for treating patients with liver cancer. Furthermore, DYRK1A is a serine/threonine kinase that phosphorylates multiple substrates associated with resistance to cancer chemotherapy, such as Met and Mcl-1 $(10,12)$. It has been reported that DYRK1 phosphorylates ID2 on
Thr27 to destabilize HIF-2 $\alpha$, but not HIF-1 $\alpha$, in a transcription-independent manner in glioblastoma under normoxic conditions (13). However, the role of DYRK1A in drug resistance under hypoxic conditions remains unclear. To the best of our knowledge, the present study demonstrated for the first time that DYRK1A could positively regulate HIF-1 $\alpha$ expression in liver cancer cells. Additionally, DYRK1A expression showed a more potent positive correlation with HIF-1 $\alpha$ compared with HIF-2 $\alpha$ in tumor tissue samples derived from patients with liver cancer from the cBioPortal database. DYRK1A and HIF-1 $\alpha$ co-expression was associated with a poor prognosis in liver cancer. The results of the present study further revealed that DYRK1A-mediated HIF-1 $\alpha$ expression could promote liver cancer chemoresistance in a hypoxic tumor microenvironment. Although DYRK1A regulated the expression of HIF-1 $\alpha$, HIF-1 $\alpha$ still could be regulated by traditional signal pathway under hypoxia, such as PI3K and MAPK $(25,26)$. Lee et al (13) and the present study demonstrated that DYRK1A is inhibited by hypoxia; it was hypothesized that it may act as a feedback loop when HIF-1 $\alpha$ is activated by PI3K or MAPK pathway under hypoxia in cancer cells. However, the hypothesis needs further investigation. 
Although sorafenib and regorafenib have been approved by the FDA to treat liver cancer, numerous resistance mechanisms including hypoxia, fibrosis, autophagy, inflammation, angiogenesis, oxidative stress and epithelial-mesenchymal transition impair the efficacy of these drugs, which still need to be resolved (27-29). Therefore, the identification of new compounds is urgently needed to overcome sorafenib and regorafenib resistance (30). Harmine, isolated from the seeds of the medical plant Peganum harmala L, is a high-affinity ATP-competitive inhibitor of DYRK1A $(31,32)$. The present data demonstrated that under hypoxic conditions, harmine reduced proliferation of liver cancer cells by regulating HIF-1 $\alpha$ expression. However, the regulation of DYRK1A was not obvious after $48 \mathrm{~h}$ treatment of harmine in liver cancer cell, thus we hypothesized that long exposure of hypoxia may enhance the accumulation of DYRK1A and HIF-1 $\alpha$. Furthermore, DYRK1A suppression increased the anti-proliferative and apoptosis induction activities of sorafenib and regorafenib by regulating HIF-1 $\alpha$ in liver cancer cells. Thus, the present findings indicated a new strategy to combat chemoresistance against liver cancer under hypoxia, but the efficacy of combining harmine with sorafenib or regorafenib in vivo may need further investigation.

DYRK1A phosphorylates the Ser-727 residue of STAT3, which is critical for B cell acute lymphoblastic leukemia development $(33,34)$. STAT3, along with HIF1, activates HIF1 target genes and drives HIF1-depedent tumorigenesis under hypoxic conditions (35). Recently, a study reported that DYRK1A can modulate the STAT3/EGFR/Met signaling pathway and that DYRK1A inhibition can facilitate the anticancer effect of AZD9291, a third-generation epidermal growth factor receptor (EGFR) tyrosine kinase inhibitor, through the STAT3 axis in EGFR wild-type NSCLC cells (11). The present findings indicated that DYRK1A directly interacts with STAT3 and may regulate the expression of HIF-1 $\alpha$ via STAT3 signaling in liver cancer cells. However, the molecular mechanism of DYRK1A in regulating STAT3 and HIF-1 $\alpha$ may need further investigation. In addition, DYRK1A suppression may sensitize liver cancer cells to sorafenib and regorafenib treatment through the STAT3/HIF- $1 \alpha /$ AKT axis. The data of the present study may thus explain the mechanism by which DYRK1A promotes resistance. Moreover, the results indicated that the DYRK1A inhibitor may be a chemosensitizing therapeutic agent in combination with sorafenib or regorafenib treatment.

In conclusion, the present study indicated that the DYRK1A regulated the expression of HIF-1 $\alpha$ through STAT3. DYRK1A suppression may sensitize liver cancer cells to sorafenib and regorafenib treatment through the STAT3/HIF-1 $\alpha /$ AKT axis. The present data identified a new DYRK1A-HIF-1 $\alpha$ pathway in chemoresistance, and DYRK1A inhibitor plus sorafenib or regorafenib might be efficacious regimens to treat liver cancer.

\section{Acknowledgements}

Not applicable.

\section{Funding}

The present study was supported by The National Natural Science Foundation of China (grant no. 81702887), The
Natural Science Foundation of Zhejiang Province (grant no. LTY21H160001), The Huadong Medicine Joint Funds of The Zhejiang Provincial Natural Science Foundation of China (grantno.LHDMY22H160001),ThePublic-service Technology Research Plan of Zhejiang (grant no. LGF21H310002), The Scientific and Technological Developing Scheme of Hangzhou City (grant no. 20191203B49), The Zhejiang Provincial Medical and Health Technology Project (grant nos. 2021433724 and 2020RC026, 2021RC104) and The Key Laboratory of Clinical Cancer Pharmacology and Toxicology Research of Zhejiang (grant no. 2020E10021).

\section{Availability of data and materials}

All data generated or analyzed during this study are included in this published article.

\section{Authors' contributions}

CZ, LHZ and YLL conceptualized the study. LWW, ZDL, MMZ and FHD curated the data. LWW, ZDL, FHD, MMZ and JW formally analyzed the data. CZ, LHZ and YLL supervised the study. CZ wrote the original draft. CZ, ZDL, LHZ, MMZ and YLL wrote, revised and edited the manuscript. YLL, ZDL, LWW, MMZ, and CZ confirm the authenticity of all the raw data. All authors read and approved the final version of the manuscript.

\section{Ethics approval and consent to participate}

Not applicable.

\section{Patient consent for publication}

Not applicable.

\section{Competing interests}

The authors declare that they have no competing interests.

\section{References}

1. Chen $\mathrm{C}$ and Lou T: Hypoxia inducible factors in hepatocellular carcinoma. Oncotarget 8: 46691-46703, 2017.

2. McKeown SR: Defining normoxia, physoxia and hypoxia in tumours-implications for treatment response. Br J Radiol 87: 20130676, 2014.

3. Liu Z, Tu K, Wang Y, Yao B, Li Q, Wang L, Dou C, Liu Q and Zheng X: Hypoxia accelerates aggressiveness of hepatocellular carcinoma cells involving oxidative stress, epithelial-mesenchymal transition and non-canonical hedgehog signaling. Cell Physiol Biochem 44: 1856-1868, 2017.

4. Lau CK, Yang ZF, Ho DW, Ng MN, Yeoh GC, Poon RT and Fan ST: An Akt/hypoxia-inducible factor-1alpha/platelet-derived growth factor-BB autocrine loop mediates hypoxia-induced chemoresistance in liver cancer cells and tumorigenic hepatic progenitor cells. Clin Cancer Res 15: 3462-3471, 2009.

5. Koh MY, Spivak-Kroizman TR and Powis G: HIF-1alpha and cancer therapy. Recent Results Cancer Res 180: 15-34, 2010.

6. Tang W and Zhao G: Small molecules targeting HIF-1 $\alpha$ pathway for cancer therapy in recent years. Bioorg Med Chem 28: 115235, 2020.

7. Kargbo RB: Selective DYRK1A inhibitor for the treatment of neurodegenerative diseases: Alzheimer, parkinson, huntington, and down syndrome. ACS Med Chem Lett 11: 1795-1796, 2020.

8. Wegiel J, Gong CX and Hwang YW: The role of DYRK1A in neurodegenerative diseases. FEBS J 278: 236-245, 2011. 
9. Laham AJ, Saber-Ayad M and El-Awady R: DYRK1A: A down syndrome-related dual protein kinase with a versatile role in tumorigenesis. Cell Mol Life Sci 78: 603-619, 2021.

10. Luna J, Boni J, Cuatrecasas M, Bofill-De Ros X, Núñez-Manchón E, Gironella M, Vaquero EC, Arbones ML, de la Luna S and Fillat C: DYRK1A modulates c-MET in pancreatic ductal adenocarcinoma to drive tumour growth. Gut 68: 1465-1476, 2019

11. Li YL, Ding K, Hu X, Wu LW, Zhou DM, Rao MJ, Lin NM and Zhang C: DYRK1A inhibition suppresses STAT3/EGFR/Met signalling and sensitizes EGFR wild-type NSCLC cells to AZD9291. J Cell Mol Med 23: 7427-7437, 2019.

12. Li Y, Zhou D, Xu S, Rao M, Zhang Z, Wu L, Zhang C and Lin N: DYRK1A suppression restrains Mcl-1 expression and sensitizes NSCLC cells to Bcl-2 inhibitors. Cancer Biol Med 17: 387-400, 2020 .

13. Lee SB, Frattini V, Bansal M, Castano AM, Sherman D, Hutchinson K, Bruce JN, Califano A, Liu G, Cardozo T, et al: An ID2-dependent mechanism for VHL inactivation in cancer. Nature 529: 172-177, 2016.

14. Dituri F, Scialpi R, Schmidt TA, Frusciante M, Mancarella S, Lupo LG, Villa E and Giannelli G: Proteoglycan-4 is correlated with longer survival in HCC patients and enhances sorafenib and regorafenib effectiveness via CD44 in vitro. Cell Death Dis 11: $984,2020$.

15. Méndez-Blanco C, Fondevila F, García-Palomo A, GonzálezGallego J and Mauriz JL: Sorafenib resistance in hepatocarcinoma: Role of hypoxia-inducible factors. Exp Mol Med 50: 1-9, 2018.

16. Tutusaus A, Stefanovic M, Boix L, Cucarull B, Zamora A Blasco L, de Frutos PG, Reig M, Fernandez-Checa JC, Marí M, et al: Antiapoptotic BCL-2 proteins determine sorafenib/regorafenib resistance and $\mathrm{BH}$-mimetic efficacy in hepatocellular carcinoma. Oncotarget 9: 16701-16717, 2018

17. Gao J, Aksoy BA, Dogrusoz U, Dresdner G, Gross B, Sumer SO Sun Y, Jacobsen A, Sinha R, Larsson E, et al: Integrative analysis of complex cancer genomics and clinical profiles using the cBioPortal. Sci Signal 6: pl1, 2013.

18. Cerami E, Gao J, Dogrusoz U, Gross BE, Sumer SO, Aksoy BA, Jacobsen A, Byrne CJ, Heuer ML, Larsson E, et al: The cBio cancer genomics portal: an open platform for exploring multidimensional cancer genomics data. Cancer Discov 2: 401-404, 2012.

19. Aguirre-Gamboa R, Gomez-Rueda H, Martínez-Ledesma E, Martínez-Torteya A, Chacolla-Huaringa R, RodriguezBarrientos A, Tamez-Peña JG and Treviño V: SurvExpress: an online biomarker validation tool and database for cancer gene expression data using survival analysis. PLoS One 8: e74250, 2013.

20. Carpenter RL and Lo HW: STAT3 target genes relevant to human cancers. Cancers (Basel) 6: 897-925, 2014

21. Rodríguez-Hernández MA, Chapresto-Garzón R, Cadenas M, Navarro-Villarán E, Negrete M, Gómez-Bravo MA, Victor VM, Padillo FJ and Muntané J: Differential effectiveness of tyrosine kinase inhibitors in 2D/3D culture according to cell differentiation, p53 status and mitochondrial respiration in liver cancer cells. Cell Death Dis 11: 339, 2020.
22. Wu LW, Zhou DM, Zhang ZY, Zhang JK, Zhu HJ, Lin NM and Zhang C: Suppression of LSD1 enhances the cytotoxic and apoptotic effects of regorafenib in hepatocellular carcinoma cells. Biochem Biophys Res Commun 512: 852-858, 2019.

23. Fernandez-Martinez P, Zahonero $\mathrm{C}$ and Sanchez-Gomez P: DYRK1A: The double-edged kinase as a protagonist in cell growth and tumorigenesis. Mol Cell Oncol 2: e970048, 2015.

24. Li L, Wei JR, Song Y, Fang S, Du Y, Li Z, Zeng TT, Zhu YH, Li Y and Guan XY: TROAP switches DYRK1 activity to drive hepatocellular carcinoma progression. Cell Death Dis 12: 125, 2021.

25. Zhang Z, Yao L, Yang J, Wang Z and Du G: PI3K/Akt and HIF1 signaling pathway in hypoxia-ischemia (review). Mol Med Rep 18: 3547-3554, 2018.

26. Kim HS, Kang YH, Lee J, Han SR, Kim DB, Ko H, Park S and Lee MS: Biphasic regulation of mitogen-activated protein kinase phosphatase 3 in hypoxic colon cancer cells. Mol Cells 44: 710-722, 2021

27. Juengpanich S, Topatana W, Lu C, Staiculescu D, Li S, Cao J, Lin J, Hu J, Chen M, Chen J and Cai X: Role of cellular, molecular and tumor microenvironment in hepatocellular carcinoma: Possible targets and future directions in the regorafenib era. Int J Cancer 147: 1778-1792, 2020.

28. Liang C, Dong Z, Cai X, Shen J, Xu Y, Zhang M, Li H, Yu W and Chen W: Hypoxia induces sorafenib resistance mediated by autophagy via activating FOXO3a in hepatocellular carcinoma. Cell Death Dis 11: 1017, 2020.

29. Tomida C, Aibara K, Yamagishi N, Yano C, Nagano H, Abe T, Ohno A, Hirasaka K, Nikawa T and Teshima-Kondo S: The malignant progression effects of regorafenib in human colon cancer cells. J Med Invest 62: 195-198, 2015.

30. Suk FM, Liu CL, Hsu MH, Chuang YT, Wang JP and Liao YJ: Treatment with a new benzimidazole derivative bearing a pyrrolidine side chain overcomes sorafenib resistance in hepatocellular carcinoma. Sci Rep 9: 17259, 2019.

31. Rüben K, Wurzlbauer A, Walte A, Sippl W, Bracher F and Becker W: Selectivity profiling and biological activity of novel $\beta$-carbolines as potent and selective DYRK1 kinase inhibitors. PLoS One 10: e0132453, 2015.

32. Göckler N, Jofre G, Papadopoulos C, Soppa U, Tejedor FJ and Becker W: Harmine specifically inhibits protein kinase DYRK1A and interferes with neurite formation. FEBS J 276: 6324-6337, 2009.

33. Bhansali RS, Rammohan M, Lee P,Laurent AP, Wen Q, Suraneni P, Yip BH, Tsai YC, Jenni S, Bornhauser B, et al: DYRK1A regulates $\mathrm{B}$ cell acute lymphoblastic leukemia through phosphorylation of FOXO1 and STAT3. J Clin Invest 131: e135937, 2021.

34. Wiechmann S, Czajkowska H, de Graaf K, Grötzinger J, Joost HG and Becker W: Unusual function of the activation loop in the protein kinase DYRK1A. Biochem Biophys Res Commun 302: 403-408, 2003

35. Pawlus MR, Wang L and Hu CJ: STAT3 and HIF1 $\alpha$ cooperatively activate HIF1 target genes in MDA-MB-231 and RCC4 cells. Oncogene 33: 1670-1679, 2014.

This work is licensed under a Creative Commons Attribution-NonCommercial-NoDerivatives 4.0 International (CC BY-NC-ND 4.0) License. 